\title{
ANÁLISE DO SISTEMA DE PRODUÇÃO E DOS FATORES DE COMPETITIVIDADE EM UMA EMPRESA DO SETOR DE MINERAÇÃO DO SUL DO BRASIL
}

\author{
ANALYSIS OF THE SYSTEM OF PRODUCTION AND \\ COMPETITIVENESS FACTORS IN A COMPANY'S MINING \\ SECTOR IN SOUTHERN BRAZIL
}

\author{
Data de submissão: 23-08-2012 \\ Aceite: $17-05-2014$ \\ Beatriz Marcondes de Azevedo ${ }^{1}$ \\ Rolf Hermann Erdmann ${ }^{2}$ \\ Andrea Cristina Trierweiller ${ }^{3}$ \\ Vanessa Ferreira Bento ${ }^{4}$
}

\section{RESUMO}

O sistema de produção é formado por subsistemas inter-relacionados, uma vez que a produção é compreendida como resultado de uma atividade oriunda de um conjunto de funções ou de esforços empregados. A flexibilidade, a inserção de novas tecnologias e o alinhamento com as demandas do mercado refletem sua multidimensionalidade e complexidade. Diante disso, o objetivo deste artigo é analisar o funcionamento do sistema produtivo de uma empresa do setor de mineração do sul do Brasil, verificando como as ações ali praticadas têm contribuído para a competitividade organizacional. Metodologicamente, trata-se de uma pesquisa exploratório-descritiva, em forma de estudo de caso, em que os dados coletados a partir de pesquisa bibliográfica e documental, de entrevistas e de observação foram analisados qualitativamente. Os resultados permitem inferir que a empresa poderia ampliar seu escopo e maximizar as ações já praticadas que apresentam resultados positivos, como é o caso, por exemplo, da mitigação dos impactos ambientais, da diminuição da periculosidade, do aumento da salubridade e da melhoria contínua via inovações em produto e processo. Por outro lado, a adoção de procedimentos estruturados de planejamento e controle, de estudo do layout e de domínio dos ciclos de produção contribuiria de forma mais assertiva para os fatores de resultado.

Palavras-chave: Competitividade. Boas práticas. Desempenho organizacional. Sistema de produção.

\footnotetext{
1 Possui graduação em Psicologia pela Universidade Federal de Santa Catarina, UFSC, graduação em Administração pela Universidade Federal de Santa Catarina, UFSC, mestrado em Psicologia pela Universidade Federal de Santa Catarina, UFSC e doutorado em Engenharia de Produção pela Universidade Federal de Santa Catarina, UFSC. Lages. Santa Catarina. Brasil. E-mail: biabizzy@gmail.com

2 Possui graduação em Engenharia Mecânica pela Universidade Federal de Santa Catarina, UFSC, graduação em Administração pela Universidade Federal de Santa Catarina, UFSC, mestrado em Engenharia de Produção pela Universidade Federal de Santa Catarina, UFSC e doutorado em Engenharia de Produção pela Universidade Federal de Santa Catarina, UFSC. Atualmente é professor titular da Universidade Federal de Santa Catarina. Florianópolis. Santa Catarina. Brasil. E-mail: erdmann@cse.ufsc.br

3 Possui graduação em Administração pela Universidade Federal de Santa Catarina, UFSC, mestrado em Engenharia de Produção pela Universidade Federal de Santa Catarina, UFSC e doutorado em Engenharia de Produção pela Universidade Federal de Santa Catarina, UFSC. Araranguá. Santa Catarina. Brasil. E-mail: andreatri@gmail.com

4 Possui graduação em Administração pela Universidade Federal de Santa Catarina, UFSC e mestrado em andamento pelo Programa de Pós-Graduação em Administração pela Universidade Federal de Santa Catarina, UFSC. Florianópolis. Santa Catarina. Brasil. E-mail: vanessafbento@gmail.com
} 


\begin{abstract}
The production system is composed of interrelated subsystems, as is understood that the production as a result of an activity derived from a set of functions or efforts employed. Flexibility, integration of new technologies and alignment with the demands of the market reflect its multidimensionality and complexity. The aim of this paper is to analyze the functioning of the productive system of a company's mining industry in southern Brazil, seeing how there actions have contributed to the prevailing organizational competitiveness. Methodologically, this is an exploratory-descriptive, in the form of case study, in which data from the bibliographic and documentary research, interviews and observation, and analyzed qualitatively. The results infer company could expand the scope and maximize the actions already being practiced successfully, for example, mitigation of environmental impacts, decreased and increased health hazard, continuous improvement from product and process innovations. Moreover, the adoption of structured procedures for planning and control, study the layout and the field of production cycles, would contribute more assertive for the factors of results.
\end{abstract}

Keywords: Competitiveness. Best practices. Organizational performance. Production system.

\title{
1 INTRODUÇÃO
}

O fenômeno "sistema de produção" é formado por subsistemas inter-relacionados, uma vez que, conforme Erdmann (2007), a produção é compreendida como resultado de uma atividade oriunda de um conjunto de funções ou de esforços empregados. Em outros termos, pode-se afirmar que são partes que, funcionando conforme um conjunto de regras, atuam sobre as entradas, processando algo e transformando-as em saídas, de acordo com os objetivos previamente estabelecidos.

Para Roman (2011), o sistema produtivo acontece por meio de uma série de inter-relações que se desencadeiam entre um conjunto variável de processos e operações que possibilitam a elaboração de um produto, seja ele um bem ou serviço. Portanto, compreendê-lo de forma isolada pode ter como consequência a perda de produtividade e de competitividade.

Nesse sentido, a flexibilidade em um processo produtivo, a inserção de novas tecnologias e o alinhamento com as demandas do mercado refletem a multidimensionalidade desse fenômeno, não fazendo mais sentido tentar compreendê-lo somente sob óticas positivistas. Assim, para conhecer e interpretar a realidade empresarial de um modo interligado e complexo, a abordagem sistêmico-complexa tem se mostrado um referencial teórico pertinente.

No intuito de possibilitar um maior entendimento sobre o modo como se estabelecem as relações em um sistema produtivo e melhor explorar o ambiente da produção a partir da ótica da complexidade, o Núcleo Interdisciplinar de Estudos em Gestão da Produção e Custos (NIEPC) do Programa de Pós-Graduação em Administração (PPGA) da Universidade Federal de Santa Catarina (UFSC) elaborou um modelo teórico-explicativo do sistema de produção composto de treze categorias de análise. Tais categorias foram estabelecidas com base no modelo criado pela London Business School sobre as boas práticas de um processo de Benchmarking Industrial (HANSON; VOSS, 1995), em que a produção enxuta, os sistemas de manufatura, a engenharia simultânea, a qualidade total, a organização e a cultura formam o sustentáculo dos principais componentes desse modelo. A estrutura proposta está orientada pela lógica de que cada categoria ou elemento estrutural do sistema tem uma relação com variáveis que conferem competitividade à organização, apoiando-as.

Nesse contexto, destaca-se o setor de mineração, caracterizado por um alto custo de produção e um forte impacto ambiental e social, além de ser um dos setores da economia com maior número de acidentes de trabalho. Tais características evidenciam a necessidade de um efetivo planejamento e controle do sistema produtivo a fim de garantir a competitividade desse setor no mercado. 
Diante do exposto, o presente artigo busca solucionar o seguinte problema de pesquisa: quais as práticas relacionadas ao sistema produtivo capazes de influenciar a competitividade em determinada empresa do setor de mineração? Decorrente deste problema, o estudo tem como objetivo analisar o funcionamento do sistema produtivo de uma empresa do setor de mineração do sul do Brasil, verificando como as ações ali praticadas têm contribuído para a competitividade organizacional, aqui entendida como a busca e o aperfeiçoamento da qualidade, da rapidez, da confiabilidade, da flexibilidade e dos custos (SLACK et al., 2002). Para tanto, serão utilizadas como base de análise as treze categorias que compõem o modelo do NIEPC.

A relevância deste estudo está ancorada no pressuposto de que uma organização que se preocupa com a gestão da produção se torna capaz de reunir seus insumos em um plano de produção aceitável, utilizando sabiamente os materiais, a capacidade e o conhecimento disponíveis em suas instalações. Em função de determinada demanda do sistema, o trabalho é programado e controlado para produzir seus bens e/ou serviços, resguardando o meio ambiente, os trabaIhadores e a comunidade circundante. Assim, os elementos constituintes do sistema produtivo, ao atuarem de forma convergente, asseguram o diferencial competitivo e, em última instância, a perenidade e a sustentabilidade da empresa.

Tendo em vista as características específicas do setor de mineração, entende-se que a aplicação da ferramenta de diagnóstico elaborada pelo NIEPC, ao permitir a identificação dos fatores de competitividade, garante a contribuição social deste estudo, uma vez que pode servir a outras empresas do mesmo setor como modelo de avaliação do sistema produtivo. Além disso, embora a ferramenta do NIEPC já tenha sido utilizada na avaliação dos mais diversos segmentos produtivos, seu uso no setor de mineração era até então inédito, indicando a originalidade do estudo.

\section{REFERENCIAL TEÓRICO}

\subsection{0 sistema de produção e suas relações complexas}

Ao considerar que o sistema de produção consiste em uma série de inter-relações de diferentes processos e operações que permitem a elaboração de um produto (bem ou serviço), Schulz (2008), por meio de estudos baseados em Hanson e Voss (1995), determinou os subsistemas estruturantes do sistema de produção a partir de dez categorias de análise: (1) Desempenho Operacional, (2) Desenvolvimento de Novos Produtos, (3) Equipamentos e Tecnologias, (4) Fábrica, (5) Investimentos, (6) Gestão Ambiental, (7) Organização e Cultura, (8) Qualidade, (9) Saúde e Segurança e (10) Tempo de Ciclo. Em um momento posterior, Silveira (2010) incorporou mais três categorias de análise: (11) Planejamento da Produção, (12) Programação da Produção e (13) Controle da Produção, totalizando, assim, as treze categorias que compõem o modelo.

As categorias Planejamento, Programação e Controle da Produção funcionam como mecanismo de impulsão ao processo produtivo, sendo, portanto, o ponto de convergência dos efeitos do sucesso ou insucesso das estratégias, das técnicas, dos métodos ou das filosofias de gestão empregadas na área da produção. Infere-se, desse modo, que as outras dez categorias, ao serem representativas de um sistema de produção, suportam o funcionamento do Planejamento e Controle da Produção (PCP).

Do ponto de vista de um diagnóstico, o sistema subdividido em categorias é confrontado com objetivos voltados à competitividade, induzindo a formação de múltiplos pontos de contato e, portanto, de oportunidades de análise e aperfeiçoamento da gestão. Com o objetivo de melhor explicitar o modelo do NIEPC, torna-se pertinente descrever e caracterizar as categorias de análise e os fatores de competitividade (prática e resultado). 


\subsection{Definição das categorias de análise}

As categorias de análise foram definidas a partir dos seguintes estudos: Schulz (2008), Sanchez (2009), Silveira (2010) e Moreira (2011). Com base na pesquisa bibliográfica, tais categorias foram definidas e caracterizadas conforme descrito a seguir.

\subsubsection{Planejamento da produção}

O planejamento de produção envolve um conjunto de procedimentos que antecede à programação e ao controle. É composto de providências normalmente duradouras em relação àquelas da programação, com destaque ao projeto do produto e ao projeto do processo. Também está incluída no planejamento a definição global de quantidades em função da demanda e da capacidade produtiva do sistema (ERDMANN, 2007).

Planejar é determinar planos de ação, baseados nos objetivos que a organização quer atingir. Esses planos irão direcionar todas as ações da organização e servirão para gestores e colaboradores apoiarem suas atividades (SLACK et al., 2002). Planos operacionais adequados permitem maior previsibilidade do processo produtivo, o que aumenta a confiabilidade da produção e das entregas. Além disso, o planejamento da produção permite que os recursos sejam utilizados de maneira racional, evitando desperdícios e reduzindo os custos operacionais, de modo que projetos de produtos e de processos cuidadosamente elaborados influenciam a qualidade do produto final (ERDMANN, 2007).

Para a elaboração do planejamento da produção, analisa-se o ambiente interno e externo e procura-se ajustar a organização de forma a atender às diversas demandas existentes, possibilitando maior flexibilidade e rapidez, uma vez que o planejamento dos tempos de processo, capacidade e demanda minimizam as chances de perdas e de tempos ociosos (SLACK et al., 2002).

\subsubsection{Programação da produção}

A programação da produção consiste em definir antecipadamente as atividades da produção. Partindo dos dados estabelecidos no planejamento, a programação caracteriza o produto (define o que será produzido, especificando dimensões e tolerâncias, características de acabamento, resistência, desempenho, consumo, cheiro e cor); roteiriza a produção (descreve o processo, especificando como o produto será elaborado e quais serão os respectivos recursos necessários, inclusive em termos de tempo de preparação e operação); e orienta quanto às quantidades a serem produzidas (ERDMANN, 2007).

Conforme Stevenson (2001), a programação da produção está relacionada com o nível de uso de equipamentos, instalações e atividades humanas. Portanto, uma programação adequada reflete na qualidade e nos resultados, ou seja, na confiabilidade e nos custos reduzidos pela minimização dos refugos e pela não necessidade do retrabalho.

Em outras palavras, a programação da produção permite que os recursos sejam utilizados de maneira mais eficiente, sem desperdício, buscando o aumento da produtividade, o que torna o processo menos oneroso. Ao considerar as diferentes demandas, a programação possibilita um processo produtivo flexível (SLACK et al., 2002).

\subsubsection{Controle da produção}

O controle de produção é uma função administrativa relacionada com "planejamento, direção e controle do suprimento de materiais e das atividades de processo em uma empresa" 
(BURBIDGE, 1981, p. 21). O controle está ligado ao conjunto de atividades que visa assegurar que as programações sejam cumpridas, que padrões sejam obedecidos, que os recursos sejam usados eficazmente e que a qualidade desejada seja obtida.

O controle da produção busca garantir que as atividades ocorram dentro do previsto, identificando e corrigindo irregularidades e permitindo o atendimento mais adequado às necessidades dos clientes, bem como a oferta de produtos mais confiáveis (ERDMANN, 2007). Ao controlar a produção, a empresa pode acompanhar adequadamente a utilização dos recursos, identificando pontos de desperdício e, consequentemente, reduzindo custos. Ademais, a organização torna-se mais eficaz em identificar falhas e pontos passíveis de melhoria, elevando a qualidade do processo produtivo e do produto. O controle permite, assim, a obtenção de informações a respeito do desenvolvimento de produtos, o que confere rapidez na colocação de novos produtos no mercado e menor tempo de entrega (ERDMANN, 2007).

\subsubsection{Organização e cultura}

A cultura organizacional é entendida como um padrão de pressuposições básicas partiIhadas por um grupo à medida que se tornem capazes de solucionar seus problemas de adaptação externa e de integração interna, de tal modo que, pelo seu sucesso, são consideradas válidas o bastante para serem ensinadas aos novos membros como o modo correto de perceber tais situações (SCHEIN, 2010). É vista, ainda, como um painel da identidade da empresa, em que os valores constitutivos do perfil organizacional assumem a forma de imagens, lendas, rituais, heróis e vilões, conflitos de papéis, dilemas comportamentais, focos de liderança, padrões de atitudes, mitos e outras dimensões simbólicas.

Tal categoria é importante no processo de análise do desempenho do sistema produtivo, uma vez que produtos de uma organização têm a sua qualidade fortemente vinculada a traços culturais. Assim, fomentar uma cultura de processos enxutos resulta em maior conscientização e comprometimento das pessoas e, em última instância, em uma produção mais rápida e eficiente. Fonseca e Silva (2009) acrescentam que o fomento de uma cultura de excelência demonstra a intenção da organização de construir um ambiente em que haja uma probabilidade maior de ocorrência de comportamentos compatíveis com o desejado.

\subsubsection{Saúde e segurança}

Essa categoria consiste em um conjunto de ações de uma organização que envolve diagnóstico, implantação de melhoria e inovações gerenciais, tecnológicas e estruturais dentro e fora do ambiente de trabalho, reduzindo os fatores de risco de acidentes e doenças e propiciando, dessa forma, condições plenas de desenvolvimento humano na realização da produção (SCHULZ, 2008; MÁSCULO; VIDAL, 2011). Para Candia et al. (2009), a gestão de saúde e segurança ganhou importância e está sendo bastante reconhecida por vários aspectos, como o desenvolvimento de locais de trabalho mais seguros, o melhor entendimento acerca das condições do trabalho e o aproveitamento das mudanças tecnológicas para a minimização dos riscos inerentes à atividade. A cultura da segurança propicia um ambiente produtivo adequado que reflete em processos produtivos confiáveis, contribuindo, assim, para a flexibilidade, rapidez e qualidade do sistema de produção.

Iramina et al. (2009) apontam que medidas como planejamento durante as etapas de avaliação de riscos e valoração destes podem poupar recursos valiosos. Tais medidas demandam tempo, mão de obra qualificada e especializada e elevado comprometimento. Entretanto, 
se realizadas adequadamente, são muito efetivas na preservação da segurança e saúde dos trabalhadores, possibilitando a redução do número de acidentes e evitando perdas de produção ou mudanças na rotina de trabalho.

\subsubsection{Equipamentos e tecnologia}

Trata-se de uma combinação de controles computacionais, comunicações, processos de manufatura e equipamentos integrados que permitem às organizações responder de forma rápida, econômica e integrada às mudanças significativas do ambiente operacional (SLACK et al., 2002).

\subsubsection{Qualidade}

É compreendida como a ausência de erros, ou seja, a capacidade que determinado bem ou serviço tem de atender, ou mesmo de superar, as expectativas do cliente de maneira consistente (SLACK et al., 2002). Deve contemplar os seguintes elementos: características operacionais principais e adicionais; confiabilidade; conformidade; durabilidade; assistência técnica; estética; e qualidade percebida (MARTINS; LAUGENI, 2006). Além disso, precisa contemplar oito fatores críticos: papel do líder, papel do departamento da qualidade, treinamento, relações interpessoais, relatórios de qualidade, gestão da qualidade dos fornecedores, design dos produtos e gestão de processos (KIM et al., 2012).

Para Lopes et al. (2013), é importante que haja o controle dos custos da qualidade, uma vez que a qualidade impacta todos os setores da empresa (comercial, operacional e financeiro). Portanto, a organização não deve ter uma visão voltada somente para a qualidade, mas também para os custos que sua falta pode provocar.

\subsubsection{Tempo de ciclo}

O tempo de ciclo é o espaço de tempo que uma unidade de um produto precisa para ser produzida. Segundo Black (1998), o nivelamento de quantidades consiste no ajuste dos lotes da produção e na sincronização dos processos com vistas à confiabilidade dos prazos e tempos, permitindo maior flexibilidade na produção.

Fernandes e Santoro (2005) acrescentam que é útil conhecer os diferentes tempos da produção e mantê-los constantes, a fim de que estes permitam tornar confiáveis as atividades de programação. Além disso, a percepção de qualidade está fortemente associada a um processo produtivo rápido ou a padrões de tempo entendidos como adequados; por isso, a constância dos ciclos praticados é vista como virtude.

\subsubsection{Gestão ambiental}

Constitui o conjunto de diretrizes e princípios que devem nortear a definição e a aplicação de instrumentos legais e institucionais de planejamento e gerenciamento ambientais, uma vez que possibilita à empresa integrar uma abordagem planejada, coordenada e organizada para a gestão dos efeitos de suas atividades, bens e serviços, que podem trazer impactos ao meio ambiente (BERNARDINI, 2008).

Frondel, Horback e Rennings (2007) entendem que a introdução de tecnologias mais limpas é suportada pelos investimentos em pesquisa e desenvolvimento. Ao encontro dessa premissa, espera-se que a equipe e os equipamentos sejam flexíveis quanto à introdução de novos conceitos ambientais. 
Nesse sentido, as empresas, com vistas a alcançar o desenvolvimento sustentável no âmbito dos objetivos definidos pela alta gerência, necessitam integrar os componentes de gestão ambiental, ou seja, as diversas áreas envolvidas na estrutura da organização. Isso demonstra a necessidade do investimento contínuo em sistemas de gestão ambiental para a geração dos resultados esperados (TRIERWEILLER et al., 2012).

\subsubsection{Desenvolvimento de novos produtos}

Relaciona-se com o estudo de desenvolvimento de produtos, que, no âmbito estratégico, pode ser visto como tentativa contínua de articular as necessidades do mercado, as possibilidades da tecnologia e as competências da empresa em um horizonte que permita que o negócio tenha continuidade (COOPER et al., 1997). O desenvolvimento de novos produtos é influenciado diretamente pelo custo, pelo tempo e pela qualidade. Nesse sentido, é possível afirmar que a integração bem-sucedida entre as áreas de marketing e de produção da empresa depende da comunicação eficaz e da cooperação entre os participantes do projeto de desenvolvimento de novos produtos, sendo esta integração reforçada por adaptações da estrutura organizacional, rotinas de solução de problemas e tecnologia da informação (SWINK; SONG, 2007).

Para Piana e Erdmann (2012), a atividade de desenvolvimento de novos produtos é capaz de criar produtos determinantes na construção da imagem e da confiabilidade. Produtos e processos inovadores, apesar de geralmente demandarem um alto investimento inicial, tendem a reduzir os custos operacionais em médio e longo prazo. O desenvolvimento de novos produtos e processos aumenta, desse modo, o leque de possibilidades de atendimento às diferentes necessidades da organização e dos consumidores. Assim, novas tecnologias de processo e novos materiais podem influenciar positivamente a qualidade.

\subsubsection{Desempenho operacional}

O desempenho operacional consiste em um sistema organizacional composto de um complexo inter-relacionado de parâmetros ou critérios de desempenho, que são a eficácia, a eficiência, a produtividade, a qualidade, a inovação e a lucratividade (SINK; TUTTLE, 1993; SWINK; NARASIMHAN; WANG, 2007). Corroboram com essa definição, baseados na revisão de literatura especializada, Grando, Tapiero e Belvedete (2007), ao assinalarem que há um consenso de que os principais indicadores do desempenho operacional de um sistema de produção são a qualidade, o tempo, o custo e a flexibilidade.

Destarte, verificações de desempenho buscam aprimorar processos e resultados e auxiliam na diversificação das atividades de execução. Pressupõe-se, assim, que, com um desempenho operacional positivo, a produção esteja bem organizada e engajada, o que possibilita uma mudança de processos de forma rápida, atendendo eficientemente às variações de demanda. Conforme Erdmann (2007), há, todavia, uma relação direta entre bom desempenho e alta flexibilidade: bons indicadores de performance podem ser reflexo de alta flexibilidade.

\subsubsection{Fábrica/instalações}

É o ambiente onde ocorre o processo produtivo. A organização e a acessibilidade do ambiente de trabalho são um requisito fundamental para a gestão da produção. À medida que há uma disposição correta das máquinas, das ferramentas e do pessoal, cria-se uma sinergia das partes, proporcionando um desempenho mais ágil e eficaz (MARTINS; LAUGENI, 2006). 
Piana e Erdmann (2012) acrescentam que ambientes adequados colaboram para a produção dentro das tolerâncias especificadas, com confiabilidade, efetuando o pedido esperado pelo cliente. A manutenção constante de equipamentos e de logística interna e externa facilita a prevenção de situações adversas, evitando gastos desnecessários e não esperados. A adequada distribuição de equipamentos e um layout flexível possibilitam ajustes necessários ao longo do processo produtivo. Equipamentos bem distribuídos na organização e boa localização influenciam a rapidez do processo de produção e o atendimento ao cliente, de forma que a ordem, a manutenção e a limpeza são essenciais para a agilidade produtiva.

\subsubsection{Investimentos}

Os investimentos são entendidos como toda capitalização aplicada aos meios produtivos da organização, podendo ser direcionados para inovação, tecnologia ou pessoas, por exemplo. O investimento nos diferentes recursos produz resultados diretos no desempenho operacional (SILVEIRA, 2010).

Há, de um lado, organizações com visão de longo prazo que focam intangíveis e, de outro, organizações que apenas investem para manter suas operações em condições mínimas. Investimentos em equipamentos novos, atualizados tecnologicamente, e em desenvolvimento de pessoas permitem desempenhos melhores e garantem a confiança no produto e no processo (SOVIENSKI; STIGAR, 2008).

Nesse sentido, Fernandes e Santoro (2005) afirmam que é relevante investir no núcleo do sistema de produção, pois o grau de prioridade atribuído ao PCP e sua aderência com expressivo volume de recursos humanos e computacionais alocados à função refletem que, "quanto maior o grau de prioridade, maior o volume alocado de recursos" (p. 32).

\subsection{Os fatores de competitividade (fatores de resultado e fatores de prática)}

Os fatores de competitividade constituem um conjunto de expressões obtidas por meio de pesquisa em fontes secundárias (ROMAN et al., 2012), que representam o entendimento sobre o que é necessário a um sistema de produção (e organizacional) para sobreviver e ser competitivo. Segundo Roman et al. (2012), entende-se como fator de competitividade aquilo que se expressa como uma real preocupação e razão de ser de cada atividade da organização. Essas "razões de fundo" ou "razões de ser" se constituem em aspectos que, ao serem claramente identificados, podem contribuir para o aperfeiçoamento organizacional ou, mais especificamente, para o aumento da performance. Em outros termos, pode-se dizer que o fator de competitividade corresponde às variáveis nas quais a organização precisa apresentar bom desempenho para sobreviver e se sobressair no mercado.

As treze categorias influenciam os fatores de competitividade, agrupados em dois blocos que se inter-relacionam entre práticas e resultados. Ambos os grupos conferem desempenho à organização. As práticas referem-se às atitudes, aos esforços ou às habilidades que geram as características de resultado, ou seja, aos elementos capazes de proporcionar competitividade direta à organização. A maneira como as práticas são aplicadas configuram os esforços adotados, isto é, os meios para o alcance dos resultados (PIANA, 2009).

Já os fatores de resultado são características fundamentais e vitais para a organização ser bem-sucedida em longo prazo e, portanto, altamente desejáveis (SLACK et al., 2002). São, assim, características capazes de proporcionar competitividade de forma direta à organização (ROMAN et al., 2012):

a) confiabilidade - significa produzir e entregar bens e/ou serviços em tempo hábil e nos 
prazos prometidos, comunicar as datas com clareza ao cliente e fazer a entrega pontualmente. Este conceito se estende às relações entre clientes internos;

b) custo - está relacionado à capacidade de produzir bens e serviços com custos mais baixos do que os concorrentes conseguem administrar. Mesmo as empresas que concorrem em outros aspectos que não o preço estão interessadas em manter seus custos baixos;

c) rapidez - significa o tempo que o cliente deve esperar desde a emissão do pedido até o recebimento efetivo do produto. É o quão rápido a organização reage às demandas;

d) flexibilidade - está relacionada com a capacidade de atender a mudanças em bens e/ ou serviços, prazos de entrega e volumes de produção. Consiste na aptidão a mudanças quando for necessário e com rapidez suficiente;

e) qualidade - significa entregar bens ou serviços conforme as especificações ou necessidades dos clientes, fazendo produtos que os clientes realmente desejem sem cometer erros e sem pecar quanto à qualidade.

Os fatores de prática, segundo Slack et al. (2002) e Roman et al. (2012), representam os padrões ou perfis de boas práticas organizacionais, ou seja, atitudes, esforços ou habilidades que a organização deve ter e que, consequentemente, refletirão em seus resultados. São eles: Alianças Estratégicas; Capital Humano; Conhecimento; Fatores Culturais; Inovação; Relacionamento com os Clientes; Responsabilidade Social; Sistemas de Controle; Técnicas de Produção; e Tecnologia da Comunicação e Informação.

A inter-relação entre as categorias de análise, os fatores de prática e os fatores de resultado é apresentada na Figura 1, exposta a seguir.

Categorias de Análise

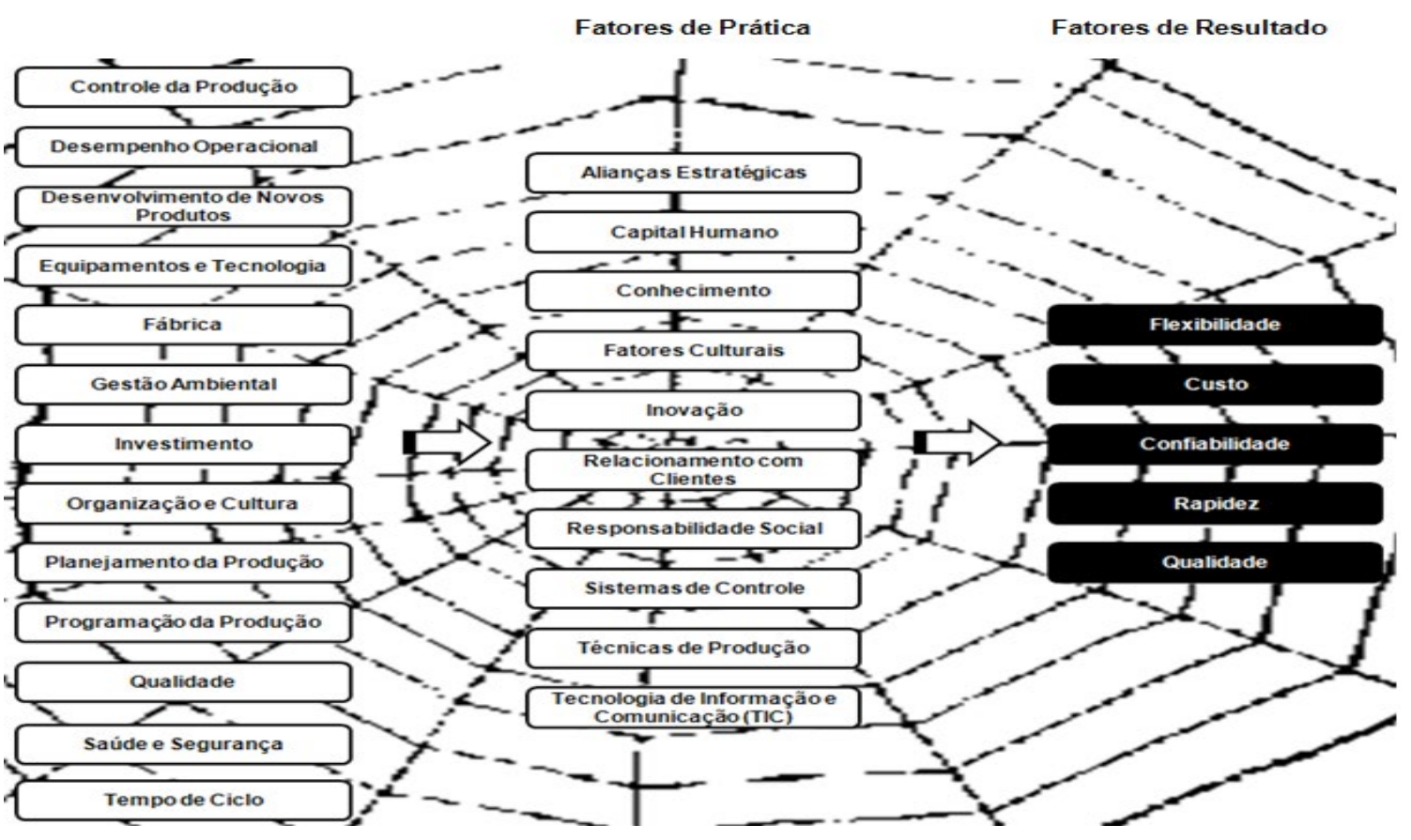

Figura 1: Modelo do NIEPC

Fonte: os autores (2012).

Sinteticamente, conforme ilustrado na Figura 1, defende-se a ideia de que cada uma das treze categorias de análise é potencialmente geradora de ações e soluções ou de exemplos 
de boas práticas que, de acordo com os preceitos de bom desempenho, produtividade, custo, rapidez, flexibilidade e confiabilidade, inferem um melhor resultado para o sistema de produção, contribuindo para a competitividade organizacional.

\section{METODOLOGIA}

O presente estudo, quanto aos objetivos, é caracterizado como exploratório-descritivo, por buscar investigar um fenômeno pouco conhecido, ou seja, o entendimento do sistema de produção a partir de treze elementos, e também por se propor a observar, registrar, analisar e correlacionar fatos dele decorrentes (MARCONI; LAKATOS, 2007). Já quanto à abordagem, tratase de uma pesquisa qualitativa, baseada em estudo de caso (MARTINS; THEÓPHILO, 2009; TRIVIÑOS, 1992). Assinala-se que não se pretendeu medir o desempenho competitivo da empresa investigada, uma vez que este estudo não contempla dados estatísticos do setor nem da organização em questão, mas analisar o funcionamento de seu sistema produtivo, verificando como as ações ali praticadas têm contribuído para a competitividade organizacional.

Em termos de coleta de dados, foram utilizados dados primários e secundários (TRIVIÑOS, 1992; MARTINS; THEÓPHILO, 2009). Os dados primários foram obtidos a partir de observação durante uma visita à empresa e da realização de entrevistas semiestruturadas com dois funcionários da média gerência. Os dados secundários, por sua vez, são provenientes de pesquisa documental e bibliográfica em livros, monografias, dissertações e artigos nacionais e internacionais, tendo como parâmetro de busca as treze categorias de análise que representam o sistema de produção e os fatores de competitividade (modelo do NIEPC).

Em relação à organização, ao tratamento e à análise dos dados, estes, depois de coletados, foram alocados nas treze categorias propostas pelo modelo e analisados qualitativamente. Em cada categoria, propôs-se uma reflexão crítica acerca das ações adotadas pela empresa, analisando de que maneira elas contribuíam para cada um dos fatores de resultado: custo, rapidez, confiabilidade, qualidade e flexibilidade.

Ressalta-se, ainda, que a abrangência deste estudo se limita à organização analisada, não sendo possível generalizar os resultados para todo o setor de mineração, embora seja possível aplicar a ferramenta em empresas do mesmo setor e também de outros segmentos, o que aliás já foi feito, por exemplo, por Moreira (2011).

\section{APRESENTAÇÃO E DISCUSSÃO DOS RESULTADOS}

A seção de apresentação e discussão dos resultados está assim estruturada: caracterização da empresa estudada e descrição de seu sistema produtivo; e elementos constituintes do sistema de produção e sua relação com os fatores de competitividade (neste item, será avaliada a postura da empresa quanto ao planejamento e à implementação de ações e projetos que possam contribuir para sua competitividade).

\subsection{Caracterização da empresa e de seu sistema produtivo}

A empresa que serviu de base para este estudo surgiu na década de 80, com o objetivo de atuar em vários ramos da Engenharia. Trata-se de uma organização do setor de mineração, uma vez que produz material pétreo em geral, desde blocos de granito até pedriscos e areia industrial, que são fabricados para consumo próprio e para comercialização. Seus consumidores 
são lojas de material de construção, concreteiras e construtoras. Produz, ainda, concreto asfáltico, em que o material pétreo figura como insumo.

Quanto ao sistema produtivo da Britamax, pode-se inferir que é do tipo produção contínua, caracterizado, segundo Erdmann (2007) e Pereira (2003), por produzir os mesmos produtos por um longo período de tempo, com pouca variação, com grandes volumes de produção e com processos sem alterações substanciais. O processo produtivo é interrompido apenas para a realização de manutenções, como, por exemplo, para a troca de correias, pois a depreciação dos equipamentos de britagem é alta. Conforme Beaumont (2005), este tipo de produção é o mais adequado, pois a empresa funciona sem nenhuma variação no processo produtivo. Por outro lado, pelo fato de todo o processo e todos os equipamentos estarem dispostos em um mesmo espaço físico, o layout da Britamax é caracterizado como arranjo funcional ou arranjo por processo (ERDMANN, 2007).

A produção de britas é de aproximadamente 100 mil toneladas por mês, sendo realizada em torno de 22 horas por dia, em três turnos. A destinação imediata dos produtos finais acontece sempre no término de cada dia, atendendo às necessidades organizacionais e os pedidos dos clientes e evitando, assim, a formação de estoques de produtos finais.

O que aumenta a produtividade é a rapidez da manutenção, gerando, por exemplo, a redução de horas ociosas por um problema técnico de um britador. Por outro lado, o nível de produção é estabelecido pela capacidade instalada e pela demanda do setor comercial. A capacidade considerada leva em conta a carga máxima que as máquinas e os equipamentos conseguem processar, bem como a disponibilidade da mão de obra.

O ponto de partida do processo produtivo (ilustrado na Figura 2) ocorre a partir da detonação da pedreira, cuja matéria-prima extraída depende da capacidade de carga do caminhão que transporta a matéria-prima da pedreira até o britador.

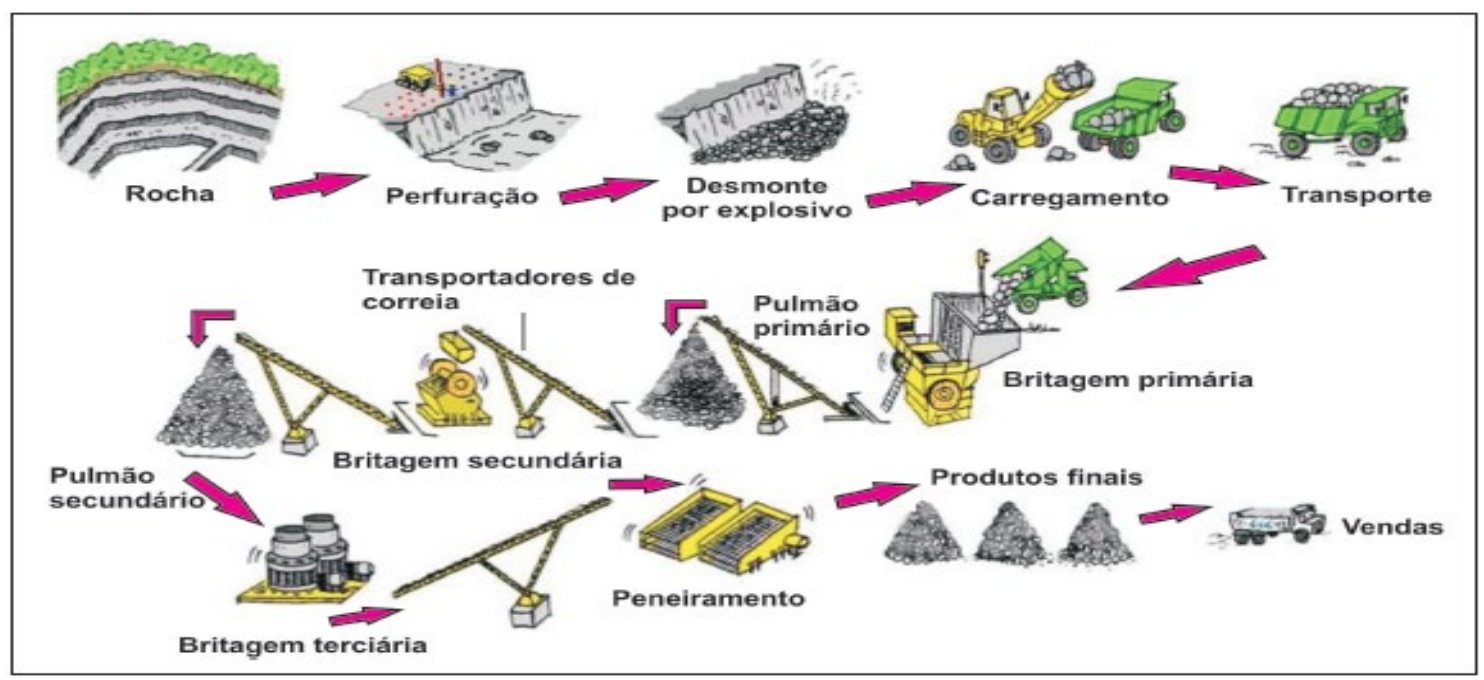

Figura 2: Fluxograma do processo produtivo

Fonte: Iramina et al. (2009, p. 506).

Com base na Figura 2, observa-se que a lavra de brita é feita a céu aberto, em meia encosta, e que as operações iniciam com a execução do plano de fogo para desmonte primário (perfuração + detonação por explosivos), que fragmenta cada trecho das bancadas da frente de lavra. Caso o material não esteja com dimensões adequadas para a entrada na planta de beneficiamento, efetua-se o desmonte secundário. Em seguida, faz-se o carregamento dos fragmentos rochosos com pás-carregadeiras em caminhões, que depositam o material em locais junto às instalações de britagem (praças de alimentação), para armazenagem temporária e alimentação 
dos britadores, ou transportam o material diretamente até os britadores primários.

As operações de beneficiamento são puramente mecânicas e consistem em britagem primária e secundária e rebritagem. Após a fragmentação no britador primário, há a formação de pilhas-pulmão, que alimentam os britadores secundários. $O$ transporte de brita entre os britadores e/ou rebritadores é feito, normalmente, por um sistema de correias transportadoras, sempre procurando aproveitar o desnível topográfico para economia na planta de beneficiamento. Para diminuir o pó em suspensão, gerado pela atividade de britagem, são utilizados sistemas de aspersores de água, instalados nas bocas dos britadores e nas correias transportadoras.

A classificação dos produtos em processo por diâmetros nominais é feita em peneiras vibratórias, com telas de aço, em silos. Geralmente, a fração retida nas peneiras superiores retorna aos rebritadores, para produzir a pedra 01 e atender à demanda atual, e a fração passante compõe as pilhas de estoque dos produtos. A expedição é mecanizada, e o transporte é feito via frete.

\subsection{Elementos constituintes do sistema de produção e sua relação com os fatores de competitividade}

Ao partir da premissa de que as três categorias que constituem o Planejamento e Controle da Produção (PCP), ou seja, o Planejamento, a Programação e o Controle da Produção, são responsáveis por ditar o ritmo e as peculiaridades do processo produtivo, elas podem ser entendidas como o núcleo do sistema de produção, ou seja, o local do qual emerge um conjunto de atitudes, ações e posturas que influenciam as demais categorias, contribuindo para a competitividade e sustentabilidade organizacional. Ou seja, o PCP é aqui caracterizado como um sistema de informações para onde devem convergir todos os esforços advindos das demais categorias, a fim de assegurar o bom funcionamento do sistema (ERDMANN, 2007).

Nesse sentido, em relação ao PCP, verifica-se que, na empresa estudada, este acontece de maneira intuitiva, sendo ainda incipiente a utilização de métodos e técnicas de produção que assegurem solidez e confiabilidade. O planejamento da produção acontece com o auxílio de duas ferramentas de gestão: a matriz SWOT e o Forecast. Então, com base, de um lado, nas forças e fraquezas, nas ameaças e oportunidades e, do outro, nas projeções de vendas e nos planos de obras, a Britamax determina o que, como e o quanto será produzido. O Forecast ainda não pode ser considerado como o programa de produção, pois representa somente previsões sujeitas a ajustes e confirmações (horizonte que pode ser de várias semanas posteriores à data do processo).

A programação e o controle na Britamax acontecem tanto diária quanto mensalmente. Há um diretor e um gerente responsáveis por acompanhar o que foi planejado e executado - tal acompanhamento ocorre em reuniões semanais em todos os setores ligados à produção. Recentemente, a empresa tem procurado formalizar e aprimorar suas ações de planejamento, programação e controle, promovendo encontros para padronizar procedimentos de preenchimento de fichas de produção para oportunizar ideias de melhorias.

Nesse sentido, a categoria Organização e Cultura pode ser entendida como uma amálgama que conecta todas as partes do sistema, que consolida seus modos de agir e influencia sua forma de diferenciação em relação aos concorrentes. A cultura permite colocar em prática os valores esposados pela Britamax: qualidade, respeito ao meio ambiente e eficiência. Sob essa ótica, o PCP levará em consideração as especificidades do produto e do processo e, portanto, o desenvolvimento de novos produtos de maneira a minimizar os danos ao meio ambiente, à saúde e à segurança das pessoas e contribuir para a flexibilidade, rapidez, qualidade dos produtos e confiabilidade nas operações e no custo do processo, uma vez que esses resultados pressupõem investimento em tecnologias mais limpas, melhores equipamentos de segurança (coletivos e individuais) e planos de produção mais assertivos. 
Dessa forma, culturas que incorporam o conceito de produção enxuta transmitem valores que levam ao comprometimento das pessoas com a utilização dos recursos de forma mais racional e econômica (SANTOS; WYSK; TORRES, 2009). A corresponsabilidade, o espírito de equipe e o comprometimento com os resultados proporcionam aptidão para atender a demandas variadas (flexibilidade). Na Britamax, tanto o início quanto o término do processo produtivo dependem, predominantemente, da competência de seus funcionários.

Em relação ao desenvolvimento de competências, a empresa tem apresentado movimentos nessa direção, com destaque a um evento que ocorreu no início do ano de 2012, em que os trabalhadores de todas as suas obras vinculados aos diferentes setores (administrativo, financeiro, suprimentos, contabilidade, custos, Recursos Humanos - RH, Tecnologia da Informação TI, jurídico, Serviço Especializado em Engenharia de Segurança e Medicina do Trabalho - SESMT, geologia, projetos sociais, qualidade, central de equipamento, oficina e transporte) se reuniram para um treinamento de reciclagem e nivelamento das informações sobre as rotinas administrativas, a fim de aprofundar o conhecimento sobre o assunto e dar sugestões de melhorias. Verificase, também, que, sempre que um novo equipamento é adquirido, os responsáveis pelo seu uso são treinados para manuseá-lo corretamente.

Com base nessas iniciativas, infere-se que a Britamax apresenta indícios de adotar e disseminar uma cultura que valorize preceitos de segurança, ambientais e econômicos. Isso vai ao encontro do que defendem Mosavi, Amirzadeh e Easy (2010), quando assinalam a importância dos fatores humanos na organização. Segundo esses autores, antes de investir na parte técnica da produção, é preciso preparar a infraestrutura humana de modo a poder contar com uma equipe de manutenção e operadores capacitados. Para tanto, as políticas de RH devem viabilizar a atração, a retenção e o desenvolvimento de talentos.

As políticas de RH adotadas pela Britamax relacionam-se com sua história. Há mais de três décadas, ela surgiu com mão de obra herdada de outra empresa que lhe deu origem; porém, ao longo dos anos, foi percebendo a necessidade de investir na área de $\mathrm{RH}$. Recentemente, firmou parceria com uma rádio local para divulgar, diariamente, vagas e suas ações. Além de oferecer uma série de benefícios (alimentação, auxílio à educação, plano de saúde, dentre outros), conta com um programa trainee, onde o treinador e o treinando recebem aumento por estarem em treinamento. Dentre os programas sociais, destaca-se o Projeto Pescar, que tem como objetivo treinar jovens para, ao final do programa, serem integrados ao quadro funcional da empresa.

No que diz respeito à Saúde e Segurança, é possível afirmar que um ambiente seguro é aquele que oferece condições adequadas para o desenvolvimento do trabalho. Isto inclui limpeza, organização, disponibilização e uso de Equipamentos de Proteção Individual (EPI) e Coletiva (EPC), cuidados com materiais e ambientes nocivos à saúde, programas e comissões internas de prevenção de acidentes, entre outras ações, com o intuito de garantir a integridade física, moral e psicológica das pessoas.

No caso da Britamax, é possível inferir que a empresa tem essa categoria como um dos subsistemas mais importantes para o bom funcionamento da produção, uma vez que, ao se enquadrar no setor de atividade com grau de risco 4, tem consciência dos investimentos necessários para evitar a ocorrência de incidentes e acidentes. Portanto, o SESMT tem atuado de forma consistente e criativa para conscientizar os trabalhadores dos riscos inerentes ao trabalho, fornecendo treinamento, fiscalizando o uso de equipamento de proteção e, ao agir interligado com subsistema de planejamento e programação da produção, comunicando com antecedência, através de um alerta pictórico, via intranet, a data e hora em que ocorrerá a detonação da pedreira, para que as pessoas evitem circular pelo pátio da empresa. Além disso, no jornal interno de publicação mensal, existe um espaço destinado às dicas de saúde e segurança. 
Os Equipamentos e Tecnologia constituem elementos fundamentais para as operações de uma organização. Os processos produtivos são dependentes das inovações tecnológicas que devem trazer facilidades de diversas ordens.

Ao focar no setor de mineração, Ferreira e Daitx (2003) destacam que ainda é comum observar a lavra do minério sendo realizada a céu aberto, em bancadas, semimecanizada, bem como o carregamento dos fragmentos rochosos efetuados com pás-carregadeiras em caminhões. As operações de beneficiamento ainda são puramente mecânicas, realizadas com britadores. $O$ transporte de brita entre os britadores e/ou rebritadores é feito, normalmente, por um sistema de correias transportadoras. A classificação por diâmetros nominais ocorre por meio de peneiras vibratórias.

Os equipamentos e a tecnologia possuem importância significativa neste setor e em especial no que diz respeito ao $\mathrm{PCP}$, pois, quando se planejam os recursos físicos necessários para a detonação de uma pedreira, é preciso estar atento ao fato de que o aumento da automação dos equipamentos é uma grande tendência (CABRAL JÚNIOR et al., 2008) e que, na medida do possível, as mudanças nos processos produtivos devem ser levadas em consideração, não apenas para maximizar a produção, mas também para minimizar os riscos inerentes à atividade. Portanto, quando a organização dispõe de equipamentos e tecnologias confiáveis, ela tende a manter a estabilidade no processo produtivo e nos produtos. Apesar de os investimentos em equipamentos e tecnologias inicialmente serem onerosos, com o tempo podem levar a uma redução de custos envolvidos nos processos produtivos.

Além disso, as inovações tecnológicas melhoram processos de produção, refletindo no aumento da qualidade. Equipamentos multifuncionais e equipes treinadas para o seu uso são capazes de atender diferentes demandas, uma vez que a introdução de equipamentos e tecnologias facilita os processos produtivos, permitindo agilidade na execução das tarefas.

Como exemplos de inovação tecnológica, pode-se citar, por exemplo, a aquisição de uma nova escavadeira de 42 toneladas, para aumentar a produção de pedra britada. Essa máquina entrou em operação em março de 2012, depois de treinamento envolvendo os responsáveis pelo seu uso. Além disso, inaugurou sua primeira obra construída com a utilização da técnica de aterro hidráulico.

Em relação à preocupação com a Qualidade de produtos e processos, resgatam-se aqui as ideias de Lopes et al. (2013), quando defendem a necessidade de uma visão sistêmica de seus efeitos tanto internamente quanto externamente à organização. Portanto, a visão ampliada da qualidade envolve essencialmente a presença de valores, crenças e atitudes que apontam na direção de fazer melhor sempre e em todas as dimensões organizacionais. Isso requer o conhecimento de práticas e o domínio de ferramentas capazes de detectar e prevenir problemas, além de gerar informações visando à melhoria.

A Britamax possui em sua estrutura um setor de qualidade com um profissional de engenharia, responsável por: elaborar e gerenciar os documentos do programa de qualidade; implantar, treinar e monitorar o programa; coordenar as atividades do comitê de qualidade; participar como membro do comitê do Projeto Pescar; responder pela escola dos funcionários da empresa; elaborar os registros da qualidade; coordenar as auditorias internas; monitorar o programa 5S; supervisionar os sistemas e métodos da empresa; e colaborar no gerenciamento da segurança do trabalho e meio ambiente.

Enfatiza-se que produtos de boa qualidade, produzidos conforme os ditames da Qualidade Total, têm maior probabilidade de gerar resultados positivos, uma vez que a alta qualidade se traduz em confiabilidade e que a ausência de qualidade acarreta danos à imagem da organização. Desse modo, a Britamax é certificada pela ISO 9000 e pelo Programa Brasileiro de Qualidade e Produtividade no Habitat (PBQP-H). As certificações obtidas pela empresa levam a pressupor 
que ali existem bons projetos de produto, equipamentos flexíveis, informações disponíveis e pessoas treinadas em suas funções e nas técnicas de qualidade.

A categoria Tempos de Ciclo envolve os diversos tempos necessários à execução das inúmeras tarefas da organização. Quanto menor for o tempo de ciclo, mais rápido será o processo produtivo.

A análise dos templos de ciclo é importante, pois, como destacado por Fernandes e Santoro (2005), ao ter o conhecimento (domínio) dos principais tempos da produção (tempo de setup, lead time, takt time e tempo morto) e desenvolver os mecanismos de acompanhamento, garantese que os prazos sejam cumpridos e que o cliente não precise aguardar mais que o tempo padrão estabelecido, além de possibilitar alterações confiáveis na programação, permitindo a introdução de novos produtos ou a alteração nos processos em andamento, de forma rápida e precisa.

Pantuza Júnior (2011) enfatiza que, nas empresas do setor de mineração, o tempo de ciclo dos equipamentos depende da frente de lavra, do tipo de caminhão e do material transportado. Nesse sentido, na formalização e implantação do PCP, busca-se assegurar que os prazos e o tamanho dos lotes possam ser cumpridos, bem como que os padrões de qualidade e confiabilidade almejados pela empresa sejam alcançados (ERDMANN, 2007). Em outras palavras, podese dizer que tempos de ciclo curtos levam à redução de custos, uma vez que mais clientes são atendidos com os mesmos recursos.

Com base nos dados coletados, infere-se que a Britamax não conhece todos os tempos envolvidos no seu processo produtivo. A empresa lida com a estimação de períodos de tempo de maneira intuitiva, tomando como base seus conhecimentos tácitos, sendo necessário, portanto, mensurar todos os tempos envolvidos desde a formalização do pedido do cliente até a entrega do produto demandado.

A Gestão Ambiental está relacionada com a preocupação da organização com o adequado tratamento dos resíduos e com a implantação de processos produtivos limpos. A busca por tais processos leva à diminuição do desperdício e ao tratamento adequado dos resíduos, podendo reduzir custos.

Mechi e Sanches (2010) destacam que o setor de mineração se depara com a necessidade frequente de escavações vultosas para a retirada do bem mineral, que resultam em grandes volumes de rejeito. $O$ processo produtivo implica a supressão de vegetação ou o impedimento de sua regeneração, de forma que, comumente, os solos remanescentes ficam expostos aos processos erosivos que podem acarretar assoreamento dos corpos d'água do entorno. A qualidade das águas dos rios, a jusante do empreendimento, pode ser prejudicada em razão da turbidez provocada pelos sedimentos finos em suspensão, assim como pela poluição causada por substâncias químicas contidas nos efluentes das áreas de mineração, tais como óleos, graxas e metais pesados.

Com frequência, a mineração provoca a poluição do ar por particulados suspensos pela atividade de lavra, pelo beneficiamento e pelo transporte, ou por gases emitidos com a queima de combustível. Outros impactos ao meio ambiente estão associados a ruídos, à sobrepressão acústica e a vibrações no solo, todos associados à operação de equipamentos e explosões. Portanto, especialmente nesse setor de atuação, por ser considerada uma empresa de grau de risco 4, pode-se inferir que esta seria a categoria que tem recebido maior atenção por uma questão tanto legal quanto ética. A Britamax, por meio da área de RH, Saúde e Segurança e Qualidade, tem se empenhado na disseminação de valores e princípios que incentivem a gestão ambiental, contribuindo para o desenvolvimento da capacidade de prevenir, investigar e minimizar as consequências de incidentes e acidentes causadores de danos ambientais. A imagem de uma empresa socialmente responsável é um fator importante de competitividade, além de contribuir para a melhoria da qualidade de vida interna e da comunidade em que está inserida. 
Com base em Trierweiller et al. (2012), é possível inferir que a política de gestão ambiental adotada na empresa se mostra presente na concepção de produtos e processos. Além disso, a Britamax tem procurado investir em treinamento de pessoal e na melhoria constante dos processos, a fim de elevar a qualidade dos bens e serviços prestados.

A Britamax tem adotado uma postura proativa nessa categoria, uma vez que, nos processos laboratoriais de controle de qualidade do material pétreo ali produzido, eram utilizados dois produtos de alto impacto ambiental: o enxofre e o tetracloroetileno. Para minimizar o potencial impacto ambiental criado a partir do uso dessas substâncias, foram adquiridos dois aparelhos: um redestilador de solventes, que permite que o tetracloroetileno seja reutilizado por até quatro vezes, e uma retífica de corpos de prova, que elimina completamente o uso do enxofre. A estimativa de redução - desde que os aparelhos foram implantados - é de dez quilos de enxofre e de 160 litros de tetracloroetileno por mês, destacando, aqui, a minimização dos custos operacionais e dos impactos ambientais.

O Desenvolvimento de Novos Produtos tem relação com facilidades no processo no que diz respeito tanto a processos mais ágeis e seguros de atendimento e produção quanto às características de produtos que auxiliem na velocidade do processo produtivo. Ao buscar a substituição de equipamentos e tecnologias por equivalentes mais modernos e seguros, possibilita-se manter os trabalhadores isolados das fontes emissoras, evitando exposição desnecessária e, consequentemente, proteção aos perigos presentes. No contexto do setor de mineração, algumas possibilidades seriam a substituição das perfuratrizes pneumáticas e hidráulicas sem cabines por modelos cabinados, a construção da cabine de controle para a britagem e peneiramento e o uso de câmeras de vídeo (IRAMINA et al., 2009).

A análise dos dados permite inferir que a Britamax tem demonstrado atenção a essa categoria, uma vez que, para contornar o problema dos resíduos do processo de britagem, em 2004, criaram-se lagoas artificiais de decantação no entorno da área industrial, que são esvaziadas periodicamente e, a cada 50 metros, barreiras físicas compostas pelo geotêxtil bidim (manta sintética que permite a drenagem de água e outros líquidos), o que garante a retenção dos resíduos sólidos. Além disso, a empresa alterou o sistema de aquecimento com caldeira a vapor para caldeira a óleo térmico e mudou o sistema de secagem de pedra de fluxo paralelo para contrafluxo, já que este último é o mais adequado devido às características do material, o que facilita o processo. Tais exemplos impactam diretamente as seguintes categorias: gestão ambiental, saúde e segurança, equipamento; e tecnologia e investimentos.

Em relação aos materiais recicláveis, a Britamax busca separar e dar a destinação adequada para os resíduos recicláveis que produz, gerando vantagens econômicas e socioambientais para si e para a comunidade local. Os pneus e as sucatas de ferro, de alumínio e de manganês que antes se acumulavam pelo pátio, favorecendo a proliferação de pragas, agora são vendidos para recicladoras. Já o papel, o papelão e parte dos EPI usados são doados para uma Associação de Recicladores local.

Quanto aos resíduos potencialmente perigosos e poluidores advindos do processo produtivo, destacam-se os resíduos laboratoriais (tetracloroetileno), os resíduos de manutenção de veículos (sólidos contaminados com óleo mineral, lodo e areia de rampa de lavagem de veículos), as lâmpadas fluorescentes, as pilhas e as baterias. Para lidar com esse problema, atualmente, a Britamax optou por contratar uma empresa licenciada para transportá-los para um aterro classe I, igualmente licenciado.

No que diz respeito ao Desempenho Operacional, parte-se do pressuposto de que, ao manter em níveis positivos os critérios de desempenho (eficácia, eficiência, produtividade, qualidade, inovação e lucratividade), a organização consegue investir em melhorias na sua performance. Nesse sentido, o PCP pode ajudar a maximizar o desempenho das operações da empresa ao permitir tanto o controle das atividades quanto o planejamento da produção. Isso contribui para tornar 
os procedimentos operacionais claros e bem definidos, seguros e em conformidade com a lei.

Especificamente em relação ao setor de mineração, Cabral Júnior et al. (2008) assinalam que o processo produtivo de britas possui características distintas quanto aos volumes de extração, à qualidade dos produtos, aos índices de produtividade, ao grau de mecanização e ao atendimento às exigências legais. Estas peculiaridades têm implicação direta sobre a confiabilidade do produto e da organização.

Sob esta ótica, a Britamax introduziu, em 2011, uma atividade mensal denominada de Café com o Presidente, que consiste em um encontro entre a direção e os colaboradores de diversas áreas da empresa, com o objetivo de trocar de ideias e experiências, possibilitando, dessa forma, a implantação de melhorias contínuas. Tal iniciativa demonstra a preocupação com o desempenho operacional, uma vez que visa avaliar os processos vigentes e atuar na melhoria contínua, resultando em aumento da qualidade percebida do produto e do processo.

Na categoria Fábrica, constata-se que a localização, a manutenção e o arranjo físico são aspectos diferenciais para uma organização, aumentando sua competitividade e seus resultados. A preocupação com essa categoria se justifica, pois, como toda atividade de mineração, a detonação de uma pedreira envolve gastos financeiros enormes, em função da soma dos pesados investimentos em equipamentos e instalações e das dificuldades referentes às inúmeras atividades para sua extração e seu beneficiamento. A troca de informações entre o PCP e as demais categorias contribui, assim, para manter elevado o volume de operação, buscando otimizar o uso dos equipamentos e garantir a alta produtividade e a sobrevivência do empreendimento, bem como o retorno do investimento (AGUIRRE; HENNIES, 2010).

A categoria Investimentos define a postura da organização quanto à melhoria de equipamentos, produtos, incrementos tecnológicos e preparação de pessoas. Nessa direção, a real vantagem competitiva no mercado não é representada somente pelo âmbito financeiro ou pelos altos investimentos em tecnologia, mas principalmente pelo investimento nas pessoas que compõem a organização (SOVIENSKI; STIGAR, 2008).

Com base na análise dos dados, é possível constatar que a Britamax não investe apenas em novas tecnologias, máquinas e equipamentos, mas também na capacitação e no desenvolvimento de seu corpo funcional. Infere-se, desse modo, que seus investimentos em ativos tangíveis e intangíveis têm contribuído para o desempenho organizacional positivo, bem como auxiliado a empresa a manter sua sustentabilidade no mercado ao longo dos anos.

Constata-se, portanto, que a preparação para enfrentar mercados dinâmicos está relacionada à vanguarda tecnológica (equipamentos multifuncionais) e à presença de pessoas capazes de exercer várias funções. O investimento em processos de produção e em colaboradores aprimora o serviço e a qualidade do resultado final.

\section{CONCLUSÃO}

A proposta deste artigo foi analisar o funcionamento do sistema produtivo de uma empresa do setor de mineração do sul do Brasil, verificando como as ações ali praticadas têm contribuído para a competitividade organizacional. Para tanto, tomou-se como base de análise as treze categorias que compõem o modelo do Núcleo Interdisciplinar de Estudos em Gestão da Produção e Custos (NIEPC). Apesar da limitação do estudo pela impossibilidade de apresentar resultados quantitativos, uma vez estes não foram disponibilizados para os pesquisadores, a análise dos resultados permite inferir que há uma equilibrada distribuição de ações positivas praticadas pela Britamax em relação aos cinco fatores de competitividade.

Com base nos resultados, verifica-se que cada uma das categorias tende a influenciar mais 
de um fator de competitividade, o que é normal tendo em vista sua abrangência de escopo. Porém, não se pode afirmar que, havendo identificação de maior número de relações entre categorias e determinado fator de competitividade, este esteja necessariamente em vantagem diante dos demais.

Nas categorias Saúde e Segurança, Gestão Ambiental, Desenvolvimento de Novos Produtos, Equipamento e Tecnologia, Qualidade, Investimentos e Organização e Cultura, a empresa poderia continuar investindo com fins de ampliação do escopo e maximização das ações que já estão sendo praticadas com êxito, como é o caso, por exemplo, da mitigação dos impactos ambientais, da diminuição da periculosidade, do aumento da salubridade, da melhoria contínua a partir de inovações em produto e processo, da qualidade de vida no trabalho e da informatização dos processos. Por outro lado, nas categorias Desempenho Operacional, Fábrica e Tempo de Ciclo, a adoção de algumas práticas, como, por exemplo, procedimentos estruturados de planejamento e controle, estudo do layout e domínio dos ciclos de produção, poderia contribuir de forma mais assertiva para os fatores de resultados, uma vez que, ao serem implantadas, assegurar-se-ia a geração de informações importantes para apoiar as micro e macro decisões do sistema produtivo.

Sugere-se também, em função da ausência de um modelo de Planejamento e Controle da Produção (PCP) estruturado na Britamax, planejamentos que viabilizem sua implantação de modo a contribuir para a assertividade das ações pertinentes aos demais subsistemas da produção, necessárias para enfrentar as crescentes exigências do mercado. O PCP é assim compreendido como um subsistema sobre o qual incidem todos os acertos e erros das demais áreas e ações da Gestão da Produção.

A contribuição deste artigo está pautada na premissa de que, a partir da apresentação das características das treze categorias de análise que compõem o modelo de diagnóstico das Relações Complexas na Administração da Produção, propõe-se uma nova alternativa para auxiliar as empresas a apontarem seus problemas no setor da produção, com o intuito de tornar seus projetos de melhorias mais eficazes.

\section{REFERENCIAS}

AGUIRRE, A. B.; HENNIES, W. T. Logística para agregados (brita e areia) em grandes centros urbanos. REM: Revista Escola de Minas, Ouro Preto, v. 63, n. 4, p. 639-643, out./dez., 2010.

BEAUMONT, N. Best practice in Australian manufacturing sites. Technovation, v. 25, $\mathrm{n}$. 11, p. 1291-1297, 2005.

BERNARDINI, S. M. E. Sistemas de gestão ambiental (ISO 14001) e de saúde e segurança ocupacional (OHSAS 18001). São Paulo: Atlas, 2008.

BLACK, J. T. 0 projeto de fábrica com futuro. Porto Alegre: Artes Médicas, 1998.

BURBIDGE, J. L. Planejamento e controle da produção. São Paulo: Atlas, 1981.

CABRAL JUNIOR, M. et al. A. A mineração no estado de São Paulo: situação atual, perspectivas e desafios para o aproveitamento dos recursos minerais. Revista Geociências, São Paulo, v. 27, n. 2, p.171-192, 2008.

CANDIA, R. C. et al. Análise de acidentes fatais na mineração: o caso da mineração no Peru. REM: Revista Escola de Minas, Ouro Preto, v. 62, n. 4, p. 517-523, 2009.

COOPER, R. G.; EDGETT, S. J.; KLEINSCHMIDT, E. J. Portfolio management in new product development: lessons from the leaders - I. Research Technology Management, v. 40, n. 5, p 16-28, 1997.

ERDMANN, R. H. Administração da Produção: planejamento, programação e controle. Florianópolis: Papa-livro, 2007.

FERNANDES, F. C. F.; SANTORO, M. C. Avaliação do grau de prioridade e do foco do Planejamento e Controle da Produção (PCP): modelos e estudos de caso. Gestão \& Produção, v. 12, n. 1, p. 25-38, jan./abr., 2005. 
FERREIRA, G.; DAITX, E. C. A mineração de areia industrial na Região Sul do Brasil. REM: Revista Escola de Minas, v. 56, n. 1, p. 59-65, jan./mar., 2003.

FONSECA, A. C. P. D.; SILVA, A. S. A perspectiva organizacional de controle em uma organização prestadora de serviços da Marinha do Brasil: o caso CASNAV. Revista de Administração da UFSM, Santa Maria, v. 2, n. 1, p. 98-115, jan./abr. 2009. Disponível em: <http://cascavel.ufsm.br/ revistas/ojs-2.2.2/index.php/reaufsm/article/ view/1280/753>. Acesso em: 20 jul. 2013.

FRONDEL, M.; HORBACH, J.; RENNINGS, K. Endof-pipe or cleaner production? An empirical comparison of environmental innovation decisions across OEDC contries. Business Strategy and the Environment, vol.16, p. 571-584, 2007.

GRANDO, A.; TAPIERO, C. S.; BELVEDETE, V. Operational performances in manufacturing and service industries: conceptual framework and research agenda. Internacional of Business Performance Management, v. 9, n. 2, p. 110-126, 2007.

HANSON, P.; VOSS, C. Benchmarking best practice in European manufacturing sites. Business Process Re-engineering \& Management Journal, v. 1, p. 60-74, 1995.

IRAMINA, W. S. et al. Identificação e controle de riscos ocupacionais em pedreira da região metropolitana de São Paulo. REM: Revista Escola de Minas, Ouro Preto, v. 62, n. 4, p. 503509, out./dez., 2009.

KIM, D-Y.; KUMAR, V.; KUMAR, U. Relationship between quality management practices and innovation. Journal of Operations Management, vol. 30, p. 295-315, 2012.

LOPES, L. F. D. et al. Uma análise do ambiente mercadológico de uma empresa do setor metal mecânico sob as perspectivas de Portes. Revista de Administração da UFSM, Santa Maria, v. 6, n. 1, p. 103-118, jan./mar. 2013. Disponível em: <http://cascavel.ufsm.br/ revistas/ojs-2.2.2/index.php/reaufsm/article/ view/2966/pdf>. Acesso em: 02 ago. 2013.
MARCONI, M. A.; LAKATOS, E. M. Técnicas de pesquisa: planejamento e execução de pesquisas, amostragens e técnicas de pesquisas, elaboração, análise e interpretação de dados. 6 ed. São Paulo: Atlas, 2007.

MARTINS, G. A.; THEÓPHILO, C. R. Metodologia da investigação científica para ciências sociais aplicadas. 2. ed. São Paulo: Atlas, 2009.

MARTINS, P. G.; LAUGENI, F. P. Administração da produção. São Paulo: Saraiva, 2006.

MÁSCULO, F. S.; VIDAL, M. C. Ergonomia: trabalho adequado e eficiente. Rio de Janeiro: Elsevier/ABEPRO, 2011.

MECHI, A.; SANCHES, D. L. Impactos ambientais da mineração no Estado de São Paulo. Estudos Avançados, v. 24, n. 68, p. 209-220, 2010.

MOREIRA, F. K. Diagnóstico de organizações complexas: o caso da unidade de pronto atendimento sul de Florianópolis. 2011. 169 f. Dissertação (Mestrado em Administração) Programa de Pós-graduação em Administração, Centro Sócio-Econômico, Universidade Federal de Santa Catarina, Florianópolis, 2011.

MOSAVI, M.; AMIRZADEH, R.; EASY, F. The just-intime production system from the perspective of manpower in Kabl Khodro company in Iran. European Journal of Economics, Finance and Administrative Sciences, v. 21, p. 133-140, jun. 2010.

PANTUZA JÚNIOR, G. Métodos de otimização multiobjetivo e desimulação aplicados ao problema de planejamento operacional de lavra em minas a céu aberto. 2011. 89 f. Dissertação (Mestrado em Engenharia Mineral) - Escola de Minas, Universidade Federal de Ouro Preto, Ouro Preto, 2011.

PEREIRA, F. A. Z. O gerenciamento do Hospital Universitário da UFSC nos níveis estratégico, tático e operacional, na percepção dos seus dirigentes. 2003. 314 f. Dissertação (Mestrado em Administração) - Programa de Pósgraduação em Administração, Centro SócioEconômico, Universidade Federal de Santa Catarina, Florianópolis, 2003. 
PIANA, J. Geração de competitividade nas organizações: um subsídio para $o$ desenvolvimento de diagnósticos complexos. 2009. 31 f. Monografia (Graduação em Administração) - Centro Sócio-Econômico, Universidade Federal de Santa Catarina, Florianópolis, 2009.

PIANA, J.; ERDMANN, R. H. Proposal and evaluation of a business game: a case on Autonomous University of Lisbon. In: Production and Operations Management Society, 2012, Chicago. Socially Responsible Operations, 2012.

ROMAN, D. Estudo sobre os fatores de competitividade organizacional e seu impacto nas condições operacionais. 2011. $175 \mathrm{f}$. Dissertação (Mestrado em Administração) Programa de Pós-graduação em Administração, Centro Sócio-Econômico, Universidade Federal de Santa Catarina, Florianópolis, 2011.

ROMAN, D. J. et al. Fatores de competitividade organizacional. Brazilian Business Review, v. 9, n. 1, p. 27-46, 2012.

SANCHEZ, T. P. Fatores da produção complexa. 2009. 140 f. Dissertação (Mestrado em Administração) - Programa de Pós-graduação em Administração, Centro Sócio-Econômico, Universidade Federal de Santa Catarina, Florianópolis, 2009.

SANTOS, J.; WYSK, R. A.; TORRES, J. M. Otimizando a produção com a metodologia lean. São Paulo: Leopardo Editora Ltda, 2009.

SCHEIN, E. H. Organizational cultural and leadership. 4. ed. San Francisco: Jossey-Bass, 2010.

SCHULZ, A. A. Relações complexas na administração da produção. 2008. 272 f. Dissertação (Mestrado em Administração) Programa de Pós-graduação em Administração, Centro Sócio-Econômico, Universidade Federal de Santa Catarina, Florianópolis, 2008.

SILVEIRA, A. M. O. L. Ferramenta de diagnóstico para organizações complexas. 2010. $214 \mathrm{f}$. Dissertação (Mestrado em Administração) Programa de Pós-graduação em Administração, Centro Sócio-Econômico, Universidade Federal de Santa Catarina, Florianópolis, 2010.

SINK, D. S.; TUTTLE, T. C. Planejamento e medição para a performance. Rio de Janeiro: Qualitymark, 1993.

SLACK, N.; JOHNSTON, R.; CHAMBERS, S. Administração da Produção. 2. ed. São Paulo: Atlas, 2002.

SOVIENSKI, F.; STIGAR, R. Recursos humanos $X$ Gestão de pessoas. GESTÃO: Revista Científica de Administração e Sistemas de Informação, v. 10, n. 10, jan./jun. 2008. Disponível em: <http://proseg.co/ media/7addfabb9962e99dffff8119ac1e1e75. pdf>. Acesso em: 01 jun. 2012.

STEVENSON, W. J. Administração das operações de produção. Rio de Janeiro: LTC, 2001.

SWINK, M.; SONG, M. Effects of marketingmanufacturing integration on new product development time and competitive advantage. Journal of Operations Management, v. 25, p. 203-217, 2007.

SWINK, M.; NARASIMHAN, R.; WANG, C. Managing beyond the factory walls: effects of four types of strategic integration on manufacturing plant performance. Journal of Operations Management, v. 25, p. 148-164, 2007.

TRIERWEILLER, A. C.; PEIXE, B. C. S.; TEZZA, R.; BORNIA, A. C. ; ANDRADE, D.F.; CAMPOS, L. M. S. Environmental management performance for Brazilian industries: measuring with the item response theory. Work (Reading, MA), v. 41, p. 2179-2186, 2012.

TRIVIÑOS, A. N. S. Introdução à pesquisa em ciências sociais: a pesquisa qualitativa em educação. São Paulo: Atlas, 1992. 